\title{
MALA HIDROELEKTRANA U ULOZI KUĆNOG AGREGATA
}

\author{
Dane Džepčeski1 ${ }^{1}$ Vladimir Stanojčić, Nemanja Milojčić, Marko Mijić², \\ Mladenko Đaković3 ${ }^{3}$ Nedeljko Todić, Anđelko Grahovac \\ ${ }^{1}$ Elektrotehnički institut „Nikola Tesla“ Univerzitet u Beogradu, Beograd, Republika Srbija \\ ${ }^{2}$ ELNOS BL, Banja Luka, Republika Srpska, BiH \\ 3 ZP „Hidroelektrane na Vrbasu“ A. D. Mrkonjić Grad, Republika Srpska, BiH \\ Stručni rad \\ DOI: $10.5937 /$ termoteh
}

\begin{abstract}
Mala hidroelektrana (mHE) koja se nalazi u okviru objekta HE „Bočac“ izgrađena je sa idejom o mogućoj višenamenskoj upotrebi. Jedan od načina upotrebe $\mathrm{mHE}$, koji je predviđen projektom, je rad $\mathrm{mHE}$ u ulozi kućnog agregata HE „Bočac“. Pre tehničkog prijema objekta mHE, izvršena su neophodna podešavanja i ispitivanja opreme hidroagregata pred njegovo puštanje u rad. U radu je prikazan deo rezultata navedenih ispitivanja, koji se pre svega odnosi na režim rada $m H E$ u ulozi kućnog agregata, odnosno kada agregat mHE napaja potrošače u ostrvskoj mreži. Navedeni režim rada agregat je sa stanovišta opreme najzahtevniji i kao takav je za analizu najinteresantniji. Prikazani su rezultati ispitivanja rada agregata prilikom trenutnog opterećenja i rasterećenja agregata, uključenjem $i$ isključenjem različitih delova izolovane $35 \mathrm{kV}$ mreže, uključenjem $i$ isključenjem potrošača u $0,4 k V$ razvodu sopstvene potrošnje $i$ potrošača u pomoćnim objektima HE „Bočac“.
\end{abstract}

Ključne reči: Mala hidroelektrana, kućni agregat, ostrvski rad.

UVOD

Agregati koji se koriste za obezbeđivanje električne energije neophodne za pokretanje elektroenergetskog objekta od velikog značaja, kakav je elektrana, iz beznaponskog stanja, moraju biti pouzdani i sa gotovo stalnom potpunom raspoloživošću. Agregati sa navedenom primenom, bilo da su dizel električni, turbo ili hidroagregati, najčešće se u inženjerskoj praksi označavaju jedinstvenim pojmom „Kućni agregati“. Hidroagregati, koji se koriste kao kućni agregati u hidroelektranama, trebalo bi da imaju najviši stepen raspoloživosti, jer koriste već postojeći vodni resurs koji je podrazumevano raspoloživ u svakoj hidroelektrani.

Korišćenje male hidroelektrane, pored njene osnovne uloge proizvodnje električne energije iz obnovljivog izvora, kao kućnog agregata, je pozitivan pristup projektu objekta ove vrste. Objekat mHE „Bočac“ sagrađen je kao višenamenski. Između ostalih, jedna od predviđenih namena je i upotreba mHE kao kućnog agregata za pokretanje iz beznaponskog stanja HE „Bočac" i buduće HE „Bočac 2".

Rad kućnog agregata je u osnovi rad agregata u ostrvu sa izolovanim opterećenjem. Navedeni način rada predstavlja najzahtevniji način rada svakog agregata. Ovde se pre svega misli na zahtevnost režima ostrvskog rada u smislu stalno prisutnih promena učestanosti i napona. Promene učestanosti i napona su posledica promena aktivnog i reaktivnog opterećenja generatora. Promene opterećenja su slučajne prirode. Slučajne su kako po vremenu svog pojavljivanja tako i po veličini same promene. Zadatak naponske i turbinske regulacije je da navedene promene budu u prihvatljivom opsegu odstupanja čije su granične vrednosti veličina manje od vrednosti veličina pri kojima dolazi do prorade električnih i hidromehaničkih zaštita agregata. Zbog razlike u vremenu odziva, koja je u slučaju sistema za turbinsku regulaciju, najmanje za red veličine, duže nego u slučaju odziva sistema za naponsku regulaciju, brz, precizan i stabilan odziv sistema za turbinsku regulaciju je, prilikom rada agregata u ostrvu, od kritične važnosti. 
Rezultati ispitivanje rada agregata i rezultati podešavanja primarne opreme agregata, prilikom rada agregata u ostrvu sa izolovanim opterećenjem, prikazani su u daljem tekstu. Prilikom prikaza i komentara rezultata, zbog njihovog značaja, naglasak je stavljen na rezultate ispitivanja i podešavanja sistema za turbinsku regulaciju.

Tabela 1: Osnovni tehnički podaci o objektu mHE „Bočac“

\begin{tabular}{|c|c|c|c|}
\hline Parametar & Oznaka & Veličina & Jedinica \\
\hline \multicolumn{4}{|l|}{ Dovod vode } \\
\hline Neto maksimalna visinska razlika & $\mathrm{H}_{\text {net }}^{\max }$ & 46 & $\mathrm{~m}$ \\
\hline Neto nominalna visinska razlika & $\mathrm{H}_{\text {net }} \mathrm{min}$ & 38 & $\mathrm{~m}$ \\
\hline Instalisani protok & $\overline{Q_{\mathrm{i}}}$ & 1400 & $\overline{1 / s}$ \\
\hline Prečnik cevovoda & $D_{c}$ & 0,8 & $\mathrm{~m}$ \\
\hline Dužina cevovoda & $\mathrm{H}_{\mathrm{c}}$ & 168 & $\mathrm{~m}$ \\
\hline \multicolumn{4}{|l|}{ Turbina } \\
\hline Turbina, vrsta & \multicolumn{3}{|c|}{ Francis } \\
\hline Nominalni pad & $\mathrm{H}_{\mathrm{n}}$ & 46 & $m$ \\
\hline Nominalni protok & $\mathrm{Q}_{\mathrm{n}}$ & 1,4 & $\mathrm{~m}^{3} / \mathrm{s}$ \\
\hline Nominalna snaga turbine & $P_{n}$ & 560 & $\mathrm{~kW}$ \\
\hline Prečnik radnog kola turbine & $D_{0}$ & 550 & $\mathrm{~mm}$ \\
\hline Masa rotora turbine & $\mathrm{m}_{\mathrm{r}}$ & 180 & $\mathrm{~kg}$ \\
\hline \multicolumn{4}{|l|}{ Generator } \\
\hline Generator, vrsta & \multicolumn{3}{|c|}{ Sinhroni } \\
\hline Nominalna prividna snaga & $S_{n}$ & 710 & $\mathrm{kVA}$ \\
\hline Nominalni faktor snage & $\cos \varphi_{n}$ & 0,8 & \\
\hline Nominalni broj obrtaja & $\mathrm{n}_{\mathrm{n}}$ & 750 & $\mathrm{~min}^{-1}$ \\
\hline Moment inercije rotora generatora & I & 90 & $\mathrm{kgm}^{2}$ \\
\hline Prečnik zamajca & $D_{z}$ & 0,5 & $\mathrm{~m}$ \\
\hline Masa zamajca & $m_{z}$ & 140 & $\mathrm{~kg}$ \\
\hline
\end{tabular}

Sistem za turbinsku regulaciju je po svojoj konstrukciji elektrohidrauličkog tipa. Električni deo turbinske regulacije realizovan je kao hardverski i programski modul na PLC-u (Programmable Logic Controller) koji je deo integrisanog sistema upravljanja, regulacije i zaštite hidroagregata. Osnovu programskog modula čini PID (Proporcional-IntegralDiferencial) algoritam regulacije, kombinovane redno-paralelne strukture. Hidraulični deo sistema za turbinsku regulaciju realizovan je korišćenjem elektrohidrauličnih razvodnika. Aktuator servomotora sprovodnog aparata turbine je elektrohidraulični razvodnik proporcionalnog dejstva. Opseg radnog pritiska hidrauličnog ulja je $90 \div 110$ bar.

\section{OPIS STRUKTURE KONFIGURACIJE OSTRVSKE MREŽE}

Na Slicil 1 prikazana je jednopolna šema ostrvske mreže na kojoj je izvršeno ispitivanje. Izvodi podrazvoda $0,4 \mathrm{kV}$ predstavljaju tačke priključenja krajnjih potrošača čiji je rad neophodan u procesu pokretanja proizvodnih agregata u HE „Bočac“ iz beznaponskog stanja. Da bi električna energija bila isporučena krajnjim potrošačima, moraju se

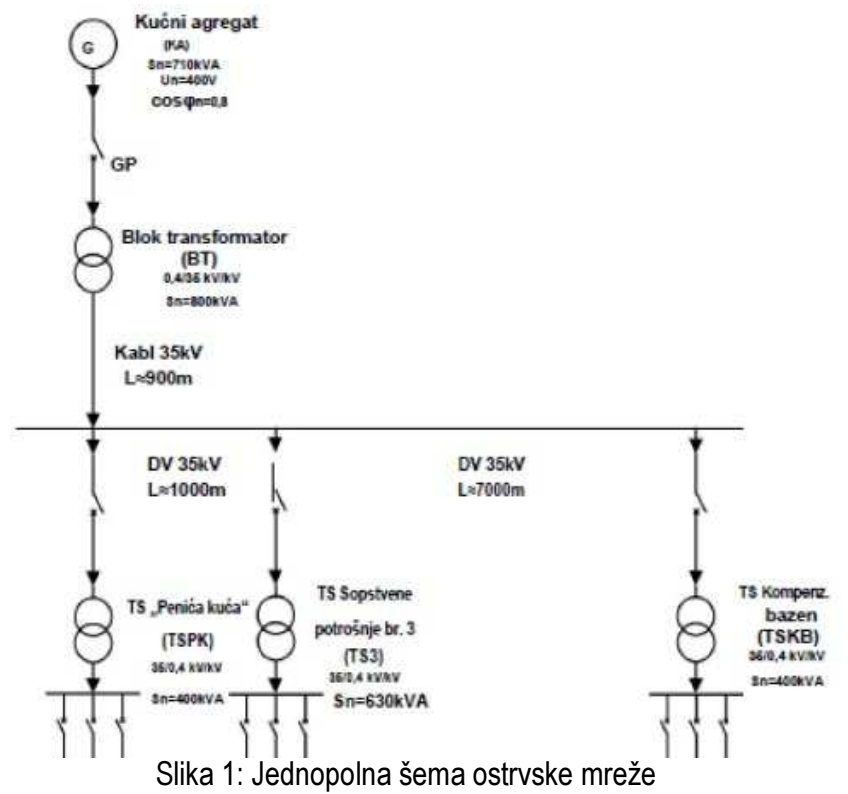
izvršiti dve transformacije napona 0,4/35 $\mathrm{kV} / \mathrm{kV}$ i 35/0,4 kV/kV. Ova činjenica je nepovoljna prevashodno sa stanovišta sistema za naponsku regulaciju kućnog agregata. Ukupna prividna snaga transformatora, uključujući i blok transformator, koja se napaja sa statorskih izvoda generatora kućnog agregata je veća od 2,2MVA. Uključenja, dva najveća od prikazanih transformatora, u prazan hod, manifestuje se kao odskočni poremećaji veći od $-10 \%$ Un i $-5 \%$ nn Takođe, da bi svi potrošači u ostrvu bili napojeni, u praznom hodu mora se još uključiti približno $0,9 \mathrm{~km}$ $35 \mathrm{kV}$-nog kabla, podužnog opterećenja7090kVAr/km kapacitivno i nadzemni 35kV-ni vod ukupne dužine $8 \mathrm{~km}$, podužnog opterećenja 3-5kVAr/km kapacitivno. Prisustvo navedenog kapacitivnog opterećenja donekle olakšava uključenje transformatora u praznom hodu. Ova činjenica je najviše izražena prilikom jednovremenog uključenja blok transformatora i kabla $35 \mathrm{kV}$. 


\section{REZULTATI ISPITIVANJA}

Pre nego što se pristupilo ispitivanju i podešavanju algoritma turbinske regulacije, koji je kao programski modul implementiran u PLC-u integrisanog sistema upravljanja, regulacije i zaštita agregata, kada agregat radi u ostrvu sa izolovanim opterećenjem, izvršena su detaljna ispitivanja i podešavanja primarne i pomoćne agregatne opreme na zaustavljenom agregatu, kada je agregat u praznom hodu i kada je agregat na mreži [1-3].

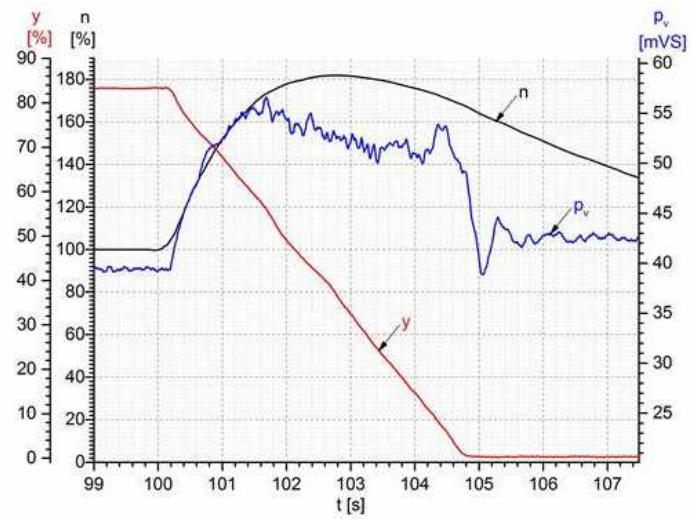

Slika 2: Zbacivanje nominalne snage generatora sa havarijskim zatvaranjem

je odnos $T_{m} / T_{w}$ blizak jedinici, potrebno koristiti elektrohidraulične regulatore sa realizovanim PID algoritmom regulacije da bi se ostvario zadovoljavajući kvalitet regulacije. $\mathrm{Na}$ istom mestu, navodi se da je odnos $T_{m} / T_{w} \approx 1$ donja granica za mogućnost ostvarivanja zadovoljavajućeg kvaliteta regulacije. U literaturi se kao kriterijum za mogućnost dobre regulacije navodi odnos $\mathrm{T}_{\mathrm{m}} / \mathrm{T}_{\mathrm{w}} \geq 3$, dok se $u[5]$ preporučuje da navedeni odnos bude $T_{m} / T_{w} \geq 4$. Provera verodostojnosti rezultat proračuna, koji se odnosi na vremensku konstantu agregata Tm, izvršena je na osnovu rezultata ogleda zbacivanja nominalne snage agregata isključenjem generatorskog prekidača. Sa Slike 2 može se videti da je strmina krive brzine obrtanja agregata, prilikom porasta brzine, vrlo velika i da je maksimalna brzina, od gotovo $182 \%$ nn, postignuta pre isteka treće sekunde nakon izazivanja poremećaja. Takođe, sa Slike 2 može se videti da

je sa minimalnim vremenom zatvaranja sprovodnog aparata turbine od $T_{f}=5,8 s$ dostignuta preporučena granica dinamičkog porasta relativnog pritiska vode ispred predturbinskog zatvarača od $35 \%$.

Imajući u vidu nepovoljni odnos $T_{m} / T_{w}$, proračun i izbor opsega parametara PID regulatora, za rad agregata $u$ ostrvu sa izolovanim opterećenjem, izvršen je pažljivo, uz uvažavanje konstrukcionih osobina hidromehaničke opreme. Izbor parametara regulatora, koji su obezbeđivali zadovoljavajući kvalitet regulacije i stabilan rad, izvršen je nakon izvođenja niza ogleda delimičnog opterećivanja i rasterećivanja agregata prikazanih na Slikama 3-6. Rezultati navedenih ogleda preuzeti su iz izveštaja o sprovedenim ispitivanjima prilikom rada agregata u ostrvu [6]. Na Slikama 2-6 sa $n$ je označena brzina obrtanja agregat, sa y je označen položaj klipa servomotora sprovodnog aparata turbine, sa $P_{G}$ aktivna snaga generatora i sa $U_{\text {an }}$ fazni napon statora generatora. $U$ nazivu navedenih slika korišćene su skraćenice, odnosno akronimi, imena transformatorskih stanica prikazanih na jednopolnoj šemi ostrva, videti Sliku 1.

Na Slici 3 prikazano je uključenje blok transformatora BT, zatim uključenje TSPK sa pripadajućim stalnim opterećenjem i na kraju uključenje asinhronih motora u 0,4kV podrazvodu TSPK. Na opterećenju agregat od 
približno $10 \% \mathrm{PGn}$, izvršen je ogled sa uključenjem i isključenjem čisto otpornog opterećenja koje je za potrebe ispitivanja bilo namenski priključeno na jedan od izvoda u 0,4kV podrazvodu TSPK. Sprovođenjem opisanog

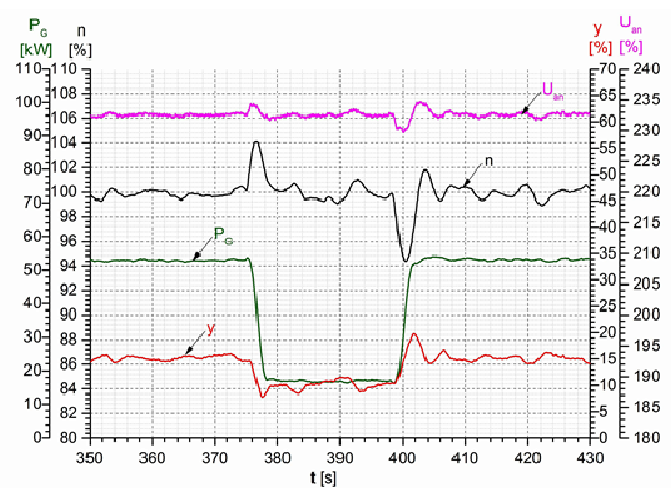

Slika 4. Uključivanje i isključivanje čisto rezistivnog tereta u $0,4 \mathrm{kV}$ razvodu TSPK na već postojeće opterećenje prikazano na Slici 2. ogleda,

ispitano je ponašanje regulatora kada je na agregat priključeno čisto omsko opterećenje koje najnepovoljnije utiče na stabilnost regulacije i čiji je koeficijent samoregulacije, pri konstantnom naponu $e_{g}=-1$. Dodatna otežavajuća okolnost je bila ta da je otporno opterećenje, vezano praktično na red sa induktivnostima namotaja transformatora BT i TSPK, tako da je ukupni koeficijent samoregulacije opterećenja u navedenom slučaju $e_{n} \leq-1$. Rezultati ogleda prikazani su na Slici 4.

Korišćeno je čisto omsko opterećenje približne snage 6\%PGn. Propadi i porasti brzine obrtanja prilikom nagle promene opterećenja od $6 \% \mathrm{PGn}$ su u granicama od +4 do $-5,5 \% \mathrm{nn}$, odnosno od +2 do $-2,75 \mathrm{~Hz}$, dok je tačnost regulacije u kvazistacionarnom stanju u opsegu koji je manji od $\pm 1 \%$ nn, odnosno $\pm 0,5 \mathrm{~Hz}$.

$\mathrm{Na}$ Slikama 5 i sl. 6 prikazani su rezultati ispitivanja odziva agregata prilikom manipulacije potrošačima na $35 \mathrm{kV}$ i $0,4 \mathrm{kV}$ u različitim delovima napojenog

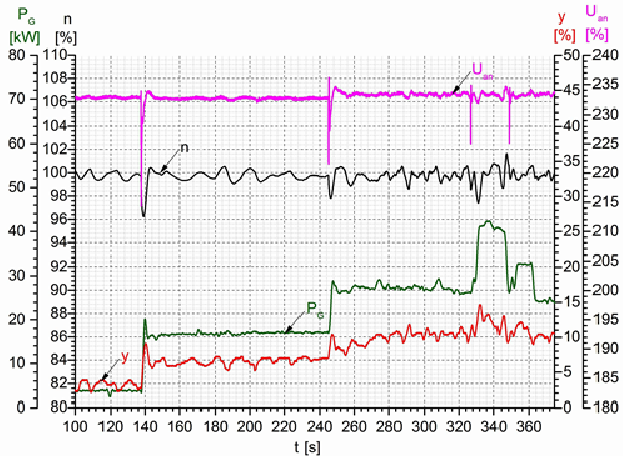

Slika 5. Uključivanje TSPK sa potrošačima i TSKB. Manipulacija hidrauličnim pumpama u $0,4 \mathrm{kV}$ podrazvodu TSKB

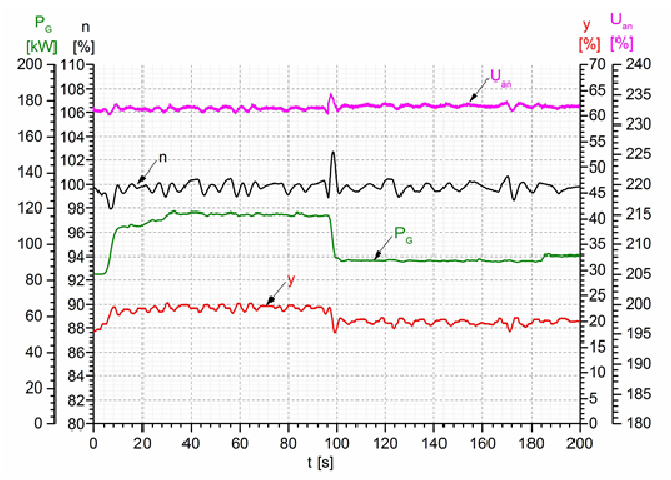

Slika 6. TSPK, TSKB i TS3 napojene. Uključenje i isključenje opterećenja koje je priključeno u 0,4kV razvodu TS3 ostrva. Na sl. 5 prikazano je uključivanje TSPK sa potrošačima, uključivanje TSKB i manipulacija hidrauličnim pumpama u $0,4 \mathrm{kV}$ podrazvodu TSKB. $\mathrm{Na}$ sl. 6 prikazano je uključenje i isključenje opterećenja koje je priključeno u $0,4 \mathrm{kV}$ podrazvodu TS3 kada su TSPK, TSKB i TS3 već bile napojene.

\section{KOMENTAR REZULTATA ISPITIVANJA}

Prilikom sprovođenja svih ogleda, sa planskim uključenjem opterećenja, koje je po veličini do $6 \% \mathrm{PGn}$, trenutni propadi i porasti brzine su bili u opsegu od $\pm 6 \%$ nn, odnosno $\pm 3 \mathrm{~Hz}$. Odzivi su dinamični i stabilni. Postoji određena nesimetričnost odziva po brzini obrtanja agregata, između slučaja opterećenje i slučaja rasterećenja agregata. Porasti brzina su po apsolutnoj vrednosti nešto manji od propada brzine. Takođe, može se uočiti postojanje prebačaja po brzini, nakon prethodnog propada brzine koje je posledica naglog opterećenja agregata. I jedna i druga pojava posledica su osobina dovoda vode kao i činjenice da je vreme otvaranja sprovodnog aparata oko $20 \%$ duže u odnosu na vreme njegovog zatvaranja.

Najveće odstupanje brzine obrtanja agregata, od nominalne vrednosti, traje dovoljno kratko tako da ne dolazi do prorade vremenskog člana nadfrekventne, odnosno podfrekventne zaštite. Takođe, promena brzina, odnosno brzina promene njene vrednosti, je manja od postavljene granične vrednosti u članu koji reaguje po gradijentu promene brzine u nadfrekventnoj i podfrekventnoj zaštiti. Praktična iskustva, prilikom rada agregata u ostrvu sa izolovanim opterećenjem, koja su 
prezentovana u člancima i literaturi su veoma oskudna. U [7] prezentovan je slučaj rada u ostrvu jednog ili dva agregata zajedno, u mHE sa ukupno instalirana tri agregata. U navedenom slučaju, promena brzine obrtanja agregata, odnosno učestanosti napona u ostrvu, kretala se u granicama $-6,2$ do $+7,5 \%$ u odnosu na svoju nominalnu vrednost. Što se tiče preporučenih vrednosti za podešavanje električnih nadfrekventnih i podfrekventnih zaštita u [8] je navedeno da opseg podešenja treba da bude u granicama od $-6 \%$ do $+5 \%$ nn, sa vremenskim zatezanjem do $0,5 \mathrm{~s}$, dok je za graničnu vrednost gradijenta promene brzine obrtanja agregata, preporučeno da bude manja ili jednaka $2,5 \mathrm{~Hz} / \mathrm{s}$ sa vremenskim zatezanjem koje nije veće od $0,5 \mathrm{~s}$. Takođe, na istom mestu je navedeno da su naznačena podešenja zaštita primenjiva za promene opterećenja agregata u opsegu 4-15\% PGn, u zavisnosti od ukupne zamajne mase prisutne u ostrvu.

\section{ZAKLJUČAK}

Agregat koji je projektovan za rad u mHE sa podrazumevanim režimom rada na mreži, može se upotrebiti i u radu u ostrvu sa izolovanim opterećenjem. Ukoliko se agregat namerava upotrebiti za rad u ostrvu, u vidu se mora imati činjenica da agregat, koji je projektovan samo za uobičajeni rad na mreži, može imati ozbiljan nedostatak zamajne mase u svojim rotirajućim delovima, koja je kao takva potrebna za ostvarivanje kvalitetne regulacije brzine obrtanja prilikom rada agregata u ostrvu. Naknadno dodavanje rotirajućih masa, ukoliko se uopšte može izvesti, često je veoma ograničeno postojećom konstrukcijom agregata. Odgovarajućim izborom delova sistema za turbinsku regulaciju, kao i pravilnim izborom realizacije i strukture regulacione funkcije kao i njenom pažljivom parametrizacijom, može se do određene granice uspešno nadomestiti nedostatak zamajnih masa i postići zadovoljavajući rezultati u regulaciji brzine obrtanja agregata i prilikom rada agregata u ostrvu sa izolovanim opterećenjem. Poštujući ograničenja kakva jedan ovakav pogon može imati, agregati u mHE koji su namenjeni prevashodno za rad na mreži, mogu se uspešno upotrebiti i kao kućni agregati koji obezbeđuju pokretanje većih elektroenergetskih objekata iz beznaponskog stanja.

\section{ZAHVALNICA}

Autori se zahvaljuju Ministarstva prosvete, nauke i tehnološkog razvoja Republike Srbije za finansijsku potporu, projekat TR33024. Takođe, autori se zahvaljuju ZP „Hidroelektrane na Vrbasu“ A. D. Mrkonjić Grad, posebno upravniku i osoblju HE „Bočac" na saradnji i tehničkoj podršci.

\section{REFERENCE}

[1] -Elektrotehnički institut „Nikola Tesla“ A.D., Izveštaj o podešavanju, ispitivanju i puštanju u rad sistema pobude kućnog agregata $H E$ „Bočac“. Beograd. 2016. Elaborat 216052, jul, str. 12..

[2] -Elektrotehnički institut „Nikola Tesla“ A.D., Izveštaj o podešavanju, ispitivanju i puštanju u rad generatorskih zaštita kućnog agregata HE „Bočac“. Beograd. 2016. Elaborat 216053,jul, str. 2.

[3] -Elektrotehnički institut „Nikola Tesla“ A.D., Izveštaj o podešavanju, ispitivanju i puštanju u rad sistema turbinske regulacije kućnog agregata $H E$ „Bočac“. Beograd. 2016. Elaborat 216054, jul, str. $6 .$.

[4] , Guide for the Application of Turbine Governing Systems for Hydroelectric Generating Units. 2004. IEEE Standard 1207-2004, 20.6.2011. ISBN: 978-0-7381-7046-6, p 24..

[5] -European Small Hydropower Association (ESHA), Guide on How to Develop a Small Hydropower Plant. 2004

[6] -Elektrotehnički institut „Nikola Tesla“ A.D., Izveštaj o ispitivanju kućnog agregata HE „Bočac“ prilikom rada agregata sa izolovanim opterećenjem. Beograd. 2016 Elaborat 216056, jul, str. 5-11.

[7] R. Jutras, C. Lafond, M. Plamondon, S. Proulx and K. Srinivasan, "Islanding tests near a mini hydro generating plant", u Proceedings of 1996 IAS Industrial and Commercial Power Systems Technical Conference. Institute of Electrical and Electronics Engineers (IEEE). 1996, str. 167-171 doi: 10.1109/icps.1996.533951

[8] -Indian Institute of Technology - Alternate Hydro Energy Center, Guidelines for small hydro development. Roorkee. 2008. September 19.

Paper submitted: $\quad$ May 12, 2016

Paper revised: July 30, 2016

Paper accepted: $\quad$ August 27, 2016
Copyrights ${ }^{\odot} 2017$ Society of Thermal Engineers of Serbia Published by the VINCA Institute of Nuclear Sciences, Belgrade, Serbia This is an open access article distributed under the CC BY-NC-ND 4.0 terms and conditions 